
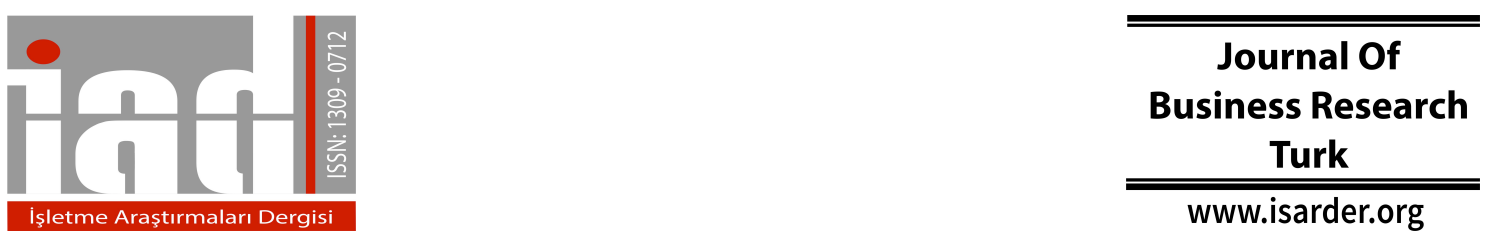

www.isarder.org

\title{
Mutual Switching Behavior between High Growth and Low Growth Economies' Stock Markets
}

\author{
Murat AKKAYA \\ Istanbul Arel University \\ İstanbul, Turkey \\ orcid.org/0000-0002-7071-8662 \\ muratakkaya@,arel.edu.tr
}

\author{
Ayben KOY \\ Istanbul Commerce University \\ Istanbul, Turkey \\ orcid.org/0000-0002-2506-6634 \\ akoy@ticaret.edu.tr
}

\begin{abstract}
Due to the evolutions in the financial markets, characteristics of markets have been changed. It has become important to discuss the markets which the fast and frequent fluctuations are observed among the regimes they belong to. There are two main purpose of the study. The first purpose of the study is to investigate whether mutual regime switching behavior exists in the selected equity markets. To investigate the importance of growth of the selected economies which the equity markets belong, is the second purpose of the study. Three regime multivariate Markov switching vector autoregressive $(\operatorname{MSI}(M)$-VAR $(p))$ models are used to define common regime switching behavior of the indices calculated.
\end{abstract}

Keywords: Regime switching, Markov, Stock Markets, Nonlinearity

\section{Introduction}

Financial markets, financial decisions and markets' mechanism are not only researched many times but also popular as well. Traditional linear models have problem in forecasting stock prices and returns. Owing to the evolutions in markets, characteristics of markets have changed as well as the stochastic behavior of their return-generating processes.

Behaviors of financial markets' change often abruptly. Not only a part of changes like jumps may be transitory, the changed behaviors of asset prices are continuous in many periods. The mean, volatility, and correlation patterns in stock return's dramatic change by the global financial crisis of 2008-2009 is viewed as an example. Fixed income, equities, foreign exchange markets and the behaviours' of many macro variables have significant relationship with the similar regime changes. Regime switching models try to explain both the sudden changes in behavior and the persistance of the new dynamics in prices (or other fundamentals) in ongoing periods (Ang and Timmermann 2011).

Markov Regime Switching (MRS) models represent the most important example of non-linear time series models. The regime in the models is defined as an unobserved state variable affecting the levels, volatility or correlations of the distributions of stock 
returns (Perez-Quirors and Timmermann 2000, Guidolin and Timmermann 2008, Chung and Yeh 2008).

MRS models are some of the popular models in financial modeling. The idea of regime changes is natural and intuitive. Also, these models explain fat tails, the periods of turbulence followed by periods of low volatility, skewness, and time-varying correlations in the behavior of many financial series. Moreover, these models can capture nonlinear stylized dynamics of asset returns in a framework based on linear specifications, or conditionally normal or log-normal distributions, within a regime (Ang and Timmermann 2011). Studies created many interesting new questions i.e. it is possible to distinguish distinct regimes in stock market returns, how the regimes differ, how frequent regime switches, when the regime switches occur and if returns and regime switches are predictable are important questions too. The answers to these questions give us new information about stock market returns (Schaller and Norden 1997).

In literature, firstly Hamilton (1989) suggests a model for non-stationary time series, named as Markov switching techniques. The outcomes of a discrete-state Markov process are parameters in this model. Hamilton studied business cycle recessions and expansions. In the study, the regimes naturally explained cycles of economic activity around a long-term trend. These regimes are closely tied to the notion of recession indicators.

The main purpose of the study is to investigate whether mutual regime switching behavior exists in the selected equity markets and whether the heteroskedasticity, skew and fat tails of the stock return distribution could be captured by The Markov switching vector autoregressive $(\operatorname{MS}(M)-\operatorname{VAR}(p))$ models with an intercept. Accordingly, $\operatorname{MSI}(M)-\operatorname{VAR}(p)$ models are used with regime shifts including the intercept in this study.

\section{Literature}

Finance literature on regime switching models may be driven by observable economic variables called tresholds or may be driven by unobservable stochastic variables as we see in MRS Models. Therewithal there is some literature on testing for the presence of structural breaks in parameters which are unpredictable break-points by using Bayesian Techniques. The MRS models represent the most important example of non-linear time series models. There is a widening literature related in non-linear behavior of the stock markets. Some of these studies are particularly deal with the MRS mechanism. In the early literature, i.e. Schwert (1989) uses a model in which returns may have high or low variance and looks for switches among return distributions determined by a two-state Markov process. In another study, Turner et al. (1989) observe whether mean, the variance or both may differ between two regimes by Markov switching model. Hamilton and Susmel (1994) use several Markov Switching ARCH models which are used to define the volatility of NYSE stock prices. They use models with different number of regimes (i.e. model with 2, 3 and 4).

Analyzing the stock markets with nonlinear models has been taken more interest since 2000. Nielse and Olesen (2000), Seddighi and Nian (2004), Marcucci (2005), Dorina and Simina (2008), Harrison and Moore (2010), Ang and Timmermann (2011), Balcilar et al. (2015), Song et al. (2016) are some of the recent studies. Nielsen and Olesen (2000) estimate a well-specified two-state regime-switching model for Danish 
stock returns by using low return-low volatility and high return-high volatility. Two regimes are identified in the model and it is observed that the indication of mean reversion is due to the recent high return-high volatility regime only. Ang and Timmermann (2011) discuss regime changes models, their effect on equilibrium asset prices in their study and try to find empirical evidence consistent with regimes in a variety of asset return series in equities, fixed income and currency markets. An equilibrium model is offered in which regimes are in fundamental processes, like consumption or dividend growth, significantly affect the dynamic properties of equilibrium asset prices. Also this equilibrium model can induce non-linear risk-return trade-offs. Finally regime switches affect investors' optimal portfolio choice.

Çevik, Korkmaz and Atukeren (2012) analyze US all shares stock returns corresponding to the New York Stock Exchange (NYSE). Following using MRS models to investigate the nonlinear structure of stock returns, the role of business confidence in manufacturing and nonmanufacturing sectors in explaining stock market regimes and regime switches are studied.

Based on the good explanation power of MRS models, the relationship between other variables and stock returns are analyzed in literature. Kim, Kim and Choi (2017) studies the effects of interest rates and foreign exchange rates in a two regimed model for the stock indices KOSPI, NIKKEI225, Dow Jones and Shanghai B. In another study $\mathrm{Zhu}, \mathrm{Su}$, You and Ren (2016) analyze the effects of oil price shocks on stock returns for oil-importing and oil-exporting countries. It is found in the study that structural oil shocks have statistically significant impacts on stock returns when switching is allowed.

\section{Data and Methodology}

\subsection{Data}

The assumption of the study is that the indices of selected emerging countries settled in the global financial portals such as finance.yahoo.com, investing.com, Bloomberg.com and BBC Business followed by the international investors. These indices are BIST100 (TURKEY), BOVESPA (Brazil), DOHA (Qatar), IDX COMPOSITE (Indonesia), IPC (Mexico), IPSA (Chile), KOSPI (South Korea), MICEX (Russia), NIFTY50 (India), South Africa 40 (South Africa) and WIG20 (Poland).

In literature, there are some evidence that economic growth have a relationship with the equity market. Some of the literature indicate that they have positive relationship (Rousseau and Wachtel (2000), Beck and Levine (2004), Ngare et all (2014), Kaplan(2008)) and others not (Arestis et all (2001), Naceur and Ghazouani (2007)). Particularly, determination of this relationship might be necessary in the emerging markets because of the lack of leading indicators (Gozbasi: 2015). Unlike the literature, we used the economic growth to form two different indices. The growth of the economies differentiate the selection of the sample. We formed an index which is computed from the equity market indices of the high economic growth emerging markets and the other emerging markets' economies have low growth. Table 1 shows the first five high growth economies in the five years periods. 
Table 1: High Growth Countries

\begin{tabular}{|l|l|l|l|l|l|}
\hline 1990-1994 & China & $\begin{array}{l}\text { South } \\
\text { Korea }\end{array}$ & Chili & Luxemburg & Ireland \\
\hline $1994-1999$ & China & Ireland & Poland & Chili & Estonia \\
\hline $2000-2004$ & China & Russia & Estonia & Latvia & Ireland \\
\hline $2005-2009$ & China & Russia & Slovakia & Turkey & $\begin{array}{l}\text { Saudi } \\
\text { Arabia }\end{array}$ \\
\hline $2010-2014$ & China & Chili & Turkey & $\begin{array}{l}\text { Saudi } \\
\text { Arabia }\end{array}$ & Russia \\
\hline
\end{tabular}

Monthly data of 2001:01-2016:2 which includes 182 observations have been used in the study. The indices are divided into two groups as an index of the high growth countries in the first five in any five years period or index of the low growth countries that could not found in the first five. The high growth economies in the five years periods are calculated from the data of the OECD. Developing countries Chile, Turkey and Russia with economic growth rates that will be leading economies were included in the calculation index HG. Also Poland and South Korea with high growth rates by 5year period between 1990-2014 period were also included to enlarge the sample. The index of the high growth economies consists of BIST100 (TURKEY), IPSA (Chile), KOSPI (South Korea), MICEX (Russia) and WIG20 (Poland). The index of the low growth economies is composite of BOVESPA (Brazil), DOHA (Qatar), IDX COMPOSITE (Indonesia), IPC (Mexico) and NIFTY50 (India). The number of the trading days differs in markets due to the holidays. Therefore using monthly data is appropriate to analyze.

The new indices named as Index HG (BIST100, IPSA, KOSPI, MICEX and WIG20) and Index LG (BOVESPA, DOHA, IDX COMPOSITE, IPC and NIFTY50) formed by arithmetic means of the groups. The market indices are shown in Figure 1 and the indices that formed by us are shown in Figure 2. We use the logarithmic differences of two new indices which may be seen in Figure 3.

Figure 1: Market Indices

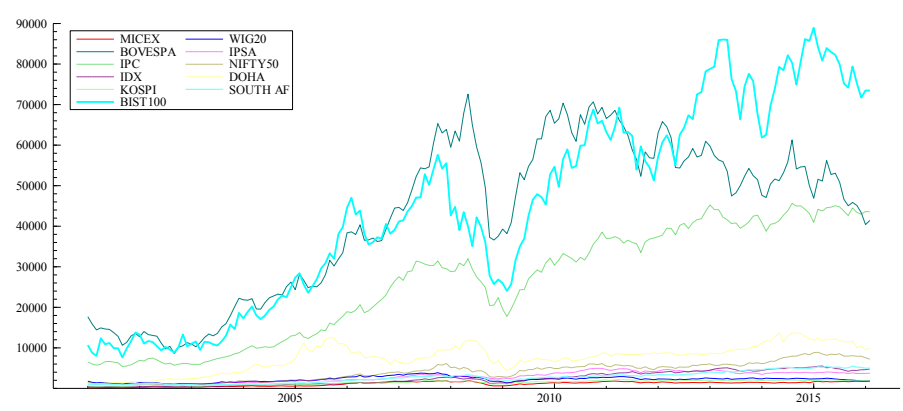

Index HG: Chile (IPSA), Poland (WIG20), Russia (MICEX), South Corea (KOSPI), Turkey (BIST100). 
Index LG: Brazil (BOVESPA), India (NIFTY50), Indonesia (IDX COMPOSITE), Mexico (IPC), Qatar (DOHA), South Africa (South Africa 40).

\section{Figure 2: Index High Growth and Index Low Growth}

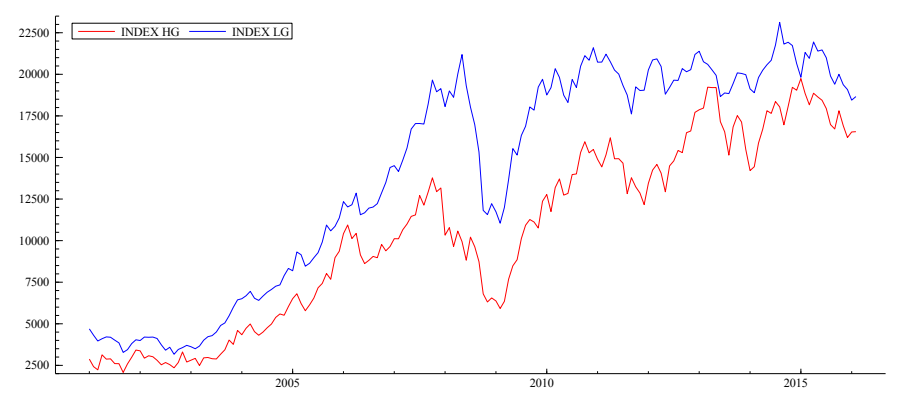

Figure 3: Logarithmic Differences of High and Low Growth Indices

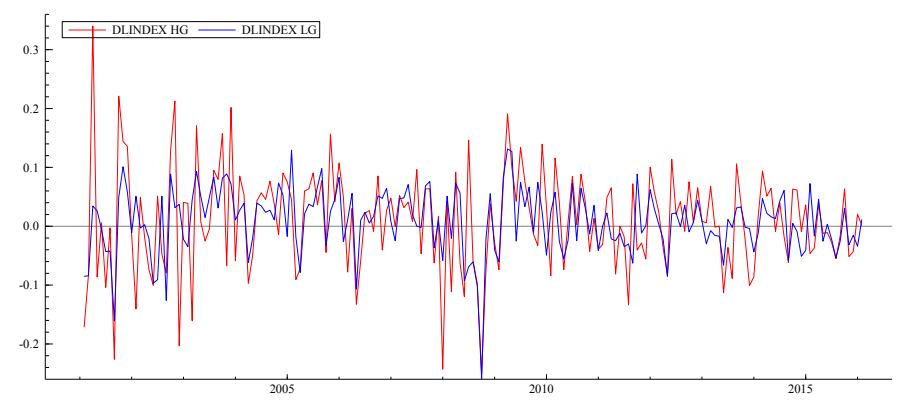

\subsection{Methodology and Model: The Markov Switching Vector Autoregressive Model}

A markov chain is composed of independent random variables. The basic idea for the MRS Model is to describe a situation or stochastic process that determines the change from the regime to the other via a Markov chain. Markov chain is used to model the behavior of a state variable or combination of variables which cannot be directly observed but determines the regime. In a MRS the state of the economy $\left(\mathrm{s}_{\mathrm{t}}\right)$ cannot be directly observed, although the time series variable $\left(\mathrm{v}_{\mathrm{t}}\right)$ can be observed. Any period of economy whose properties depend on the observation values, is obtained as probability. At the same time those observations are supposed to be dependent on the properties of the regime. When the state of the economy in the Markov regime is determined, the next regime can be expressed as a probability (Bildirici et all 2000).

The idea behind regime-switching models is that the parameters of a, say, Kdimensional vector time series process $\left(\mathrm{y}_{\mathrm{t}}\right)$ depend upon an unobservable regime variable $s_{t}$ which represents the probability of being in a particular state of the world (Krolzig 2000).

$$
\mathrm{p}(\mathrm{yt} \mid \mathrm{Yt}-1 ; \mathrm{Xt} ; \mathrm{st} \text { : }
$$

$$
\begin{array}{ll}
\mathrm{f}(\mathrm{yt} \mid \mathrm{Yt}-1 ; \mathrm{Xt} ; \Theta 1) & \text { if } \mathrm{st}=1 \\
\mathrm{f}(\mathrm{yt} \mid \mathrm{Yt}-1 ; \mathrm{Xt} ; \Theta M) & \text { if } \mathrm{st}=\mathrm{M}
\end{array}
$$

$\mathrm{Xt}$ : exogenous variables; $\Theta$ is the parameter vector associated with regime $\mathrm{M}$. 
In Markov Switching models the regime-generating process is an ergodic Markov chain with a finite number of states defined by the transition probabilities (Krolzig 2000).

$$
\mathrm{pij}=\operatorname{Pr}(\mathrm{st}+1=\mathrm{j} \mid \mathrm{st}=\mathrm{i}) ; \sum P i j=1 M j=1 ; \mathrm{i}, \mathrm{j}=\{1, . ., \mathrm{M}\}
$$

st follows an ergodic M-state Markov process with an irreducible transition matrix:

$$
\mathbf{P}=\left|\begin{array}{ccc}
p_{: .} & \ldots & p_{1 i i} \\
\ldots & \ldots & \ldots \\
p_{i i 1} & \ldots & p_{\text {wii }}^{z}
\end{array}\right|
$$

The probability which regime is in operation at time $t$ conditional on the information at time $t-1$ only depends on the statistical inference on $s t-1$ :

$$
\operatorname{Pr}(s t \mid Y t-1 ; X t ; S t-1)=\operatorname{Pr}(s t \mid s t-1)
$$

Markov Switching time series analysis is firstly implemented by Hamilton (1989) in the business cycle. Hamilton reexamined the possibility that macroeconomic variables evolve on a cyclical time scale. The relationship between economic and calendar time in turn depends on the economic history of the process, such as whether the economy has been in a cyclical expansion or contraction.

The main different kinds of the model are MSM and MSI models. In MSM Model, the regime switches according to the conditional mean $\left(\mu_{\mathrm{t}}\right)$, on the other hand in MSI Model, the regime switches according to the constant $\left(\mathrm{c}_{\mathrm{st}}\right)$.

MSM Model: $\mathrm{y}_{\mathrm{t}}-\mu_{\mathrm{t}}=\phi\left(\mathrm{y}_{\mathrm{t}-1}-\mu_{\mathrm{t}-1}\right)+\mathrm{u}_{\mathrm{t}}$

MSI Model: $\mathrm{y}_{\mathrm{t}}-\mathrm{c}_{\mathrm{st}}=\phi \mathrm{y}_{\mathrm{t}-1}+\mathrm{u}_{\mathrm{t}}$

MSIH Model: $\mathrm{y}_{\mathrm{t}}-\mathrm{c}_{\mathrm{st}}=\phi \mathrm{y}_{\mathrm{t}-1}+\mathrm{u}_{\mathrm{t}+} \Omega^{1 / 2}$

$\phi$ is an $\mathrm{n} \times \mathrm{n}$ matrix of regime-dependent autoregressive coefficients

$\mathrm{u}_{\mathrm{t}}$ is an $\left(\mathrm{n}^{*} 1\right)$ unobservable zero mean white noise vector process

Matrix $\Omega^{1 / 2}$ represents the factor applicable to state $\mathrm{s}_{\mathrm{t}}$ in a state-dependent Choleski factorization of the variance covariance matrix of variable (y) $\Omega \mathrm{s}_{\mathrm{t}}$.

$$
\Omega \mathrm{s}_{\mathrm{t}}=\operatorname{Var}\left[y_{t} \mid \boldsymbol{x}_{t-1}, s_{t}\right] \quad ;
$$

$\varkappa_{\mathrm{t}-1}$ : denotes time $\mathrm{t}-1$ information of all past observations and states.

A linear vector autoregression(VAR) model is a natural extension of the univariate autoregressive model to dynamic multivariate time series. A Markov switching vector autoregressive model allows asymmetric (regime dependent) inference for causality (Balc1lar and Ozdemir, 2013).

The basic $\mathrm{p}$ lagged $\operatorname{VAR}(p)$ model process is:

$\mathrm{y}_{\mathrm{t}}=\mathrm{c}+\left[\mathrm{A}_{1} \mathrm{y}_{\mathrm{t}-1}+\ldots+\mathrm{A}_{\mathrm{p}} \mathrm{y}_{\mathrm{t}-\mathrm{p}}\right]+\mathrm{u}_{\mathrm{t}}$

$A_{n}$ is $(n * n)$ coefficient matrices

The general form of a Markov-switching vector autoregressive (MS-VAR) process is (Krolzig 1998, 2000):

$$
\mathrm{y}_{\mathrm{t}}=\mathrm{c}\left(\mathrm{s}_{\mathrm{t}}\right)+\left[\mathrm{A}_{1}\left(\mathrm{~s}_{\mathrm{t}}\right) \mathrm{y}_{\mathrm{t}-1}+\ldots+\mathrm{A}_{\mathrm{p}}\left(\mathrm{s}_{\mathrm{t}}\right) \mathrm{y}_{\mathrm{t}-\mathrm{p}}\right]+\mathrm{u}_{\mathrm{t}}
$$


A VAR with regime shifts in the mean is called a $\operatorname{MSM}(M)-\operatorname{VAR}(p)$ process:

$$
\begin{aligned}
& \mathrm{y}_{\mathrm{t}}=\mu\left(\mathrm{s}_{\mathrm{t}}\right)+\mathrm{A}_{1}\left(\mathrm{~s}_{\mathrm{t}}\right)\left(\mathrm{y}_{\mathrm{t}-1}-\mu\left(\mathrm{s}_{\mathrm{t}-1}\right)\right)+\ldots+\mathrm{A}_{\mathrm{p}}\left(\mathrm{s}_{\mathrm{t}}\right)\left(\mathrm{y}_{\mathrm{t}-\mathrm{p}}-\mu\left(\mathrm{s}_{\mathrm{t}-\mathrm{p}}\right)\right)+\mathrm{u}_{\mathrm{t}} \\
& \mathrm{u}_{\mathrm{t}} \sim \mathrm{NID}\left(0, \Sigma\left(\mathrm{s}_{\mathrm{t}}\right)\right)
\end{aligned}
$$

If the regime shifts affect the intercept of the VAR, this is called a $\operatorname{MSI}(M)$ $\operatorname{VAR}(p)$ process:

$$
\mathrm{y}_{\mathrm{t}}=\mathrm{c}\left(\mathrm{s}_{\mathrm{t}}\right)+\mathrm{A}_{1}\left(\mathrm{~s}_{\mathrm{t}}\right) \mathrm{y}_{\mathrm{t}-1}+\ldots+\mathrm{A}_{\mathrm{p}}\left(\mathrm{s}_{\mathrm{t}}\right) \mathrm{y}_{\mathrm{t}-\mathrm{p}}+\mathrm{u}_{\mathrm{t}}
$$

After a shift in regime, the transition to the new (conditional) mean is smooth in an MSI-VAR and once-and-for-all in an MSM-VAR. MSM-VAR and MSI-VAR processes represent the subclass of MS-VAR processes for which optimal predictor can be derived analytically and computationally effective algorithms can be constructed easily (Krolzig 1998, 2000).

If the regime shifts affect the intercept of the VAR and the model includes a variance covariance matrix, this is called a $\operatorname{MSIH}(M)-\operatorname{VAR}(p)$ process:

$$
\mathrm{y}_{\mathrm{t}}=\mathrm{c}\left(\mathrm{s}_{\mathrm{t}}\right)+\mathrm{A}_{1}\left(\mathrm{~s}_{\mathrm{t}}\right) \mathrm{y}_{\mathrm{t}-1}+\ldots+\mathrm{A}_{\mathrm{p}}\left(\mathrm{s}_{\mathrm{t}}\right) \mathrm{y}_{\mathrm{t}-\mathrm{p}}+\mathrm{u}_{\mathrm{t}+} \Omega^{1 / 2}
$$

$\operatorname{MSIH}(M)-\operatorname{VAR}(p)$ model means "Markov switching", "Intercept regime dependent", "Vector autoregressive", "heteroskedastic" model (Guidolin 2006).

It is possible to analyze in MS-VAR models how other variables are affected if shocks applied to a variable. Impulse response functions of the models show these relations in different regimes. For example, if the model includes two variables and has got three regimes, there should be six $(2 * 3=6)$ relations to analyze.

\section{Results}

2 and 3 regime switching models are applied with different lags to the logarithmic differences of Index High Growth and Index Low Growth. We select the models with a Davies' criteria smaller than 0.05 which reject the Davies criteria's null hypothesis of linearity. The information criterions of the models are shown in Table 2, 3,4, 5 and 6.

MS(p)-VAR(1) models are shown in Table 2. According to the information criterions, MSIAH(3)-VAR(1), MSIA(3)-VAR(1) and MSIH(3)-VAR(1) models are successful in examining the relationships.

All of the three models have three regimes. The first regime is recession, the second regime is moderate growth and the third regime is expansion. Besides, each of the models has got an intercept. We look to LR linearity criterion to see how much the non-linear model explains the relation more than the linear model. Of the three models, MSIAH(3)-VAR(1) is the most powerful one. 
Table 2: The Information Criterions of The Models with 1 Lag

\begin{tabular}{|l|l|l|l|l|l|l|}
\hline Model & log-likelihood & AIC & HQ & SIC & LR Linearity & DAVIES \\
\hline MSI(2)-VAR(1) & 508.7168 & -5.5080 & -5.4145 & -5.2774 & 12.4398 & 0.0267 \\
\hline MSI(3)-VAR(1) & 521.2291 & -5.5803 & -5.4437 & -5.2443 & 37.4643 & 0.0000 \\
\hline MSIH(2)-VAR(1) & 515.2425 & -5.5471 & -5.4321 & -5.2633 & 25.4911 & 0.0027 \\
\hline MSIH(3)-VAR(1) & $\mathbf{5 2 9 . 8 5 4 5}$ & $\mathbf{- 5 . 6 0 9 5}$ & $\mathbf{- 5 . 4 2 9 7}$ & $\mathbf{- 5 . 1 6 6 0}$ & $\mathbf{5 4 . 7 1 5 2}$ & $\mathbf{0 . 0 0 0 0}$ \\
\hline MSIA(2)-VAR(1) & 513.5625 & -5.5174 & -5.3951 & -5.2158 & 22.1312 & 0.0223 \\
\hline MSIA(3)-VAR(1) & $\mathbf{5 3 3 . 4 3 2 5}$ & $\mathbf{- 5 . 6 2 7 0}$ & $\mathbf{- 5 . 4 3 2 8}$ & $\mathbf{- 5 . 1 4 8 1}$ & $\mathbf{6 1 . 8 7 1 2}$ & $\mathbf{0 . 0 0 0 0}$ \\
\hline MSIAH(2)-VAR(1) & 521.1572 & -5.5684 & -5.4246 & -5.2136 & 37.3205 & 0.0007 \\
\hline MSIAH(3)-VAR(1) & $\mathbf{5 4 2 . 6 4 2 7}$ & $\mathbf{- 5 . 6 6 2 7}$ & $\mathbf{- 5 . 4 2 5 4}$ & $\mathbf{- 5 . 0 7 7 3}$ & $\mathbf{8 0 . 2 9 1 4}$ & $\mathbf{0 . 0 0 0 0}$ \\
\hline MSM(2)-VAR(1) & 509.5899 & -5.5177 & -5.4242 & -5.2871 & 14.1859 & 0.0126 \\
\hline MSM(3)-VAR(1) & 518.5688 & -5.5508 & -5.4141 & -5.2137 & 32.1436 & 0.0001 \\
\hline MSMH(2)-VAR(1) & 518.0824 & -5.7055 & -5.5886 & -5.4173 & 37.7581 & 0.0000 \\
\hline MSMH(3)-VAR(1) & 523.7047 & -5.6671 & -5.4844 & -5.2167 & 49.0027 & 0.0000 \\
\hline
\end{tabular}

MS(p)-VAR(2) models are shown in Table 3. According to the information criterions, MSIAH(3)-VAR(2), MSIA(3)-VAR(2) and MSIH(3)-VAR(2) models are more successful than others. Besides, each of these three models is more successful than the same kind of model with one lag.

Table 3: The Information Criterions of The Models with 2 Lag

\begin{tabular}{|l|l|l|l|l|l|l|}
\hline Model & log-likelihood & AIC & HQ & SIC & LR Linearity & DAVIES \\
\hline MSI(3)-VAR(2) & 522.4891 & -5.5809 & -5.4148 & -5.1713 & 42.6193 & 0.0000 \\
\hline MSIH(2)-VAR(2) & 523.1376 & -5.6216 & -5.4772 & -5.2655 & 43.9164 & 0.0000 \\
\hline MSIH(3)-VAR(2) & $\mathbf{5 2 9 . 3 3 3 6}$ & $\mathbf{- 5 . 5 9 0 3}$ & $\mathbf{- 5 . 3 8 0 9}$ & $\mathbf{- 5 . 0 7 3 9}$ & $\mathbf{5 6 . 3 0 8 4}$ & $\mathbf{0 . 0 0 0 0}$ \\
\hline MSIA(2)-VAR(2) & 520.1440 & -5.5323 & -5.3518 & -5.0872 & 37.9292 & 0.0012 \\
\hline MSIA(3)-VAR(2) & $\mathbf{5 4 1 . 8 3 9 3}$ & $\mathbf{- 5 . 6 1 8 3}$ & $\mathbf{- 5 . 3 3 6 7}$ & $\mathbf{- 4 . 9 2 3 9}$ & $\mathbf{8 1 . 3 8 9 8}$ & $\mathbf{0 . 0 0 0 0}$ \\
\hline MSIAH(2)-VAR(2) & 527.6837 & -5.5831 & -5.3809 & -5.0845 & 53.0085 & 0.0000 \\
\hline MSIAH(3)-VAR(2) & $\mathbf{5 5 8 . 7 3 1 3}$ & $\mathbf{- 5 . 7 4 0 0}$ & $\mathbf{- 5 . 4 1 5 1}$ & $\mathbf{- 4 . 9 3 8 7}$ & $\mathbf{1 1 5 . 1 0 3 8}$ & $\mathbf{0 . 0 0 0 0}$ \\
\hline MSM(3)-VAR(2) & 519.2245 & -5.5444 & -5.3783 & -5.1349 & 36.0902 & 0.0000 \\
\hline MSMH(2)-VAR(2) & 519.1486 & -5.6721 & -5.5260 & -5.3119 & 38.0936 & 0.0000 \\
\hline MSMH(3)-VAR(2) & 525.4634 & -5.6416 & -5.4297 & -5.1192 & 50.7230 & 0.0000 \\
\hline
\end{tabular}


MS(p)-VAR(3) models are shown in Table 4. The most powerful three models are MSIAH(3)-VAR(3), MSIA(3)-VAR(3) and MSIAH(2)-VAR(3).

Table 4: The Information Criterions of The Models with 3 Lag

\begin{tabular}{|l|l|l|l|l|l|l|}
\hline Model & log-likelihood & AIC & HQ & SIC & LR Linearity & DAVIES \\
\hline MSI(3)-VAR(3) & 523.1960 & -5.5752 & -5.3795 & -5.0926 & 27.1251 & 0.0005 \\
\hline MSIH(2)-VAR(3) & 527.5158 & -5.6575 & -5.4835 & -5.2285 & 35.7645 & 0.0000 \\
\hline MSIH(3)-VAR(3) & $\mathbf{5 3 2 . 6 6 7 1}$ & $\mathbf{- 5 . 6 1 4 2}$ & $\mathbf{- 5 . 3 7 5 0}$ & $\mathbf{- 5 . 0 2 4 4}$ & $\mathbf{4 6 . 0 6 7 1}$ & $\mathbf{0 . 0 0 0 1}$ \\
\hline MSIA(2)-VAR(3) & $\mathbf{5 4 0 . 1 3 6 3}$ & $\mathbf{- 5 . 6 9 8 2}$ & $\mathbf{- 5 . 4 5 8 9}$ & $\mathbf{- 5 . 1 0 8 3}$ & $\mathbf{6 1 . 0 0 5 6}$ & $\mathbf{0 . 0 0 0 0}$ \\
\hline MSIA(3)-VAR(3) & $\mathbf{5 5 1 . 8 7 5 1}$ & $\mathbf{- 5 . 6 2 7 8}$ & $\mathbf{- 5 . 2 5 8 1}$ & $\mathbf{- 4 . 7 1 6 2}$ & $\mathbf{8 4 . 4 8 3 2}$ & $\mathbf{0 . 0 0 0 0}$ \\
\hline MSIAH(2)-VAR(3) & $\mathbf{5 4 5 . 7 6 5 1}$ & $\mathbf{- 5 . 7 2 7 7}$ & $\mathbf{- 5 . 4 6 6 7}$ & $\mathbf{- 5 . 0 8 4 2}$ & $\mathbf{7 2 . 2 6 3 2}$ & $\mathbf{0 . 0 0 0 0}$ \\
\hline MSIAH(3)-VAR(3) & $\mathbf{5 6 4 . 6 8 9 8}$ & $\mathbf{- 5 . 7 0 4 4}$ & $\mathbf{- 5 . 2 9 1 2}$ & $\mathbf{- 4 . 6 8 5 5}$ & $\mathbf{1 1 0 . 1 1 2 6}$ & $\mathbf{0 . 0 0 0 0}$ \\
\hline MSM(3)-VAR(3) & 520.8555 & -5.5489 & -5.3532 & -5.0663 & 22.4380 & 0.0035 \\
\hline MSMH(2)-VAR(3) & 521.5481 & -5.6540 & -5.4786 & -5.2216 & 38.8869 & 0.0000 \\
\hline MSMH(3)-VAR(3) & 526.6752 & -5.6099 & -5.3688 & -5.0154 & 49.1356 & 0.0000 \\
\hline
\end{tabular}

MS(p)-VAR(4) models are shown in Table 5. MSIAH(3)-VAR(4), MSIA(3)VAR(4) and MSIA(2)-VAR(4) models are the most powerful models of the four autoregressive lagged models. Besides, MSIH(3)-VAR(4) model is more successful than the 2 and 3 lagged MSIH(3)-VAR(q) models.

Table 5: The Information Criterions of The Models with 4 Lag

\begin{tabular}{|l|l|l|l|l|l|l|}
\hline Model & log-likelihood & AIC & HQ & SIC & LR Linearity & DAVIES \\
\hline MSI(2)-VAR(4) & 515.1621 & -5.5386 & -5.3566 & -5.0899 & 16.4716 & 0.0046 \\
\hline MSI(3)-VAR(4) & 524.0250 & -5.5709 & -5.3453 & -5.0146 & 34.1974 & 0.0000 \\
\hline MSIH(2)-VAR(4) & 527.3496 & -5.6424 & -5.4386 & -5.1399 & 40.8466 & 0.0000 \\
\hline MSIH(3)-VAR(4) & $\mathbf{5 3 6 . 0 2 1 6}$ & $\mathbf{- 5 . 6 3 8 7}$ & $\mathbf{- 5 . 3 6 9 4}$ & $\mathbf{- 4 . 9 7 4 7}$ & $\mathbf{5 8 . 1 9 0 6}$ & $\mathbf{0 . 0 0 0 0}$ \\
\hline MSIA(2)-VAR(4) & $\mathbf{5 4 4 . 1 3 6 4}$ & $\mathbf{- 5 . 6 8 5 2}$ & $\mathbf{- 5 . 3 8 6 8}$ & $\mathbf{- 4 . 9 4 9 4}$ & $\mathbf{7 4 . 4 2 0 2}$ & $\mathbf{0 . 0 0 0 0}$ \\
\hline MSIA(3)-VAR(4) & $\mathbf{5 6 8 . 4 7 0 8}$ & $\mathbf{- 5 . 7 1 1 5}$ & $\mathbf{- 5 . 2 5 3 1}$ & $\mathbf{- 4 . 5 8 1 0}$ & $\mathbf{1 2 3 . 0 8 9 0}$ & $\mathbf{0 . 0 0 0 0}$ \\
\hline MSIAH(2)-VAR(4) & $\mathbf{5 4 3 . 7 0 1 3}$ & $\mathbf{- 5 . 6 4 6 3}$ & $\mathbf{- 5 . 3 2 6 1}$ & $\mathbf{- 4 . 8 5 6 8}$ & $\mathbf{7 3 . 5 4 9 9}$ & $\mathbf{0 . 0 0 0 0}$ \\
\hline MSIAH(3)-VAR(4) & $\mathbf{5 8 4 . 2 1 3 1}$ & $\mathbf{- 5 . 8 2 1 6}$ & $\mathbf{- 5 . 3 1 9 5}$ & $\mathbf{- 4 . 5 8 3 5}$ & $\mathbf{1 5 4 . 5 7 3 6}$ & $\mathbf{0 . 0 0 0 0}$ \\
\hline MSM(2)-VAR(4) & 512.9587 & -5.5136 & -5.3317 & -5.0650 & 12.0629 & 0.0314 \\
\hline MSM(3)-VAR(4) & 519.2287 & -5.5167 & -5.2911 & -4.9604 & 24.6048 & 0.0014 \\
\hline MSMH(2)-VAR(4) & 524.6460 & -5.6437 & -5.4391 & -5.1393 & 43.1582 & 0.0000 \\
\hline MSMH(3)-VAR(4) & 532.0003 & -5.6250 & -5.3547 & -4.9585 & 57.8666 & 0.0000 \\
\hline
\end{tabular}


MS(p)-VAR(5) models are shown in Table 6. MSIAH(3)-VAR(5), MSIA(3)VAR(5) and MSIA(2)-VAR(5) models are the most three powerful models in the table. By the $5^{\text {th }}$ lag, the LR linearity criteria of the models begin to decline.

Table 6: The Information Criterions of The Models with 5 Lag

\begin{tabular}{|l|l|l|l|l|l|l|}
\hline Model & log-likelihood & AIC & HQ & SIC & LR Linearity & DAVIES \\
\hline MSI(2)-VAR(5) & 513.8137 & -5.5092 & -5.2974 & -4.9868 & 16.1521 & 0.0053 \\
\hline MSI(3)-VAR(5) & 521.9946 & -5.5340 & -5.2783 & -4.9035 & 32.5139 & 0.0000 \\
\hline MSIH(2)-VAR(5) & 525.8205 & -5.6116 & -5.3778 & -5.0351 & 40.1655 & 0.0000 \\
\hline MSIH(3)-VAR(5) & $\mathbf{5 3 4 . 5 8 8 6}$ & $\mathbf{- 5 . 6 0 9 0}$ & $\mathbf{- 5 . 3 0 9 4}$ & $\mathbf{- 4 . 8 7 0 4}$ & $\mathbf{5 7 . 7 0 1 9}$ & $\mathbf{0 . 0 0 0 0}$ \\
\hline MSIA(2)-VAR(5) & $\mathbf{5 4 7 . 3 8 5 9}$ & $\mathbf{- 5 . 6 6 3 5}$ & $\mathbf{- 5 . 3 0 5 5}$ & $\mathbf{- 4 . 7 8 0 8}$ & $\mathbf{8 3 . 2 9 5 9}$ & $\mathbf{0 . 0 0 0 0}$ \\
\hline MSIA(3)-VAR(5) & $\mathbf{5 8 0 . 7 3 1 7}$ & $\mathbf{- 5 . 7 4 7 0}$ & $\mathbf{- 5 . 1 9 9 0}$ & $\mathbf{- 4 . 3 9 5 9}$ & $\mathbf{1 4 9 . 9 8 8 0}$ & $\mathbf{0 . 0 0 0 0}$ \\
\hline MSIAH(2)-VAR(5) & $\mathbf{5 4 8 . 2 7 3 4}$ & $\mathbf{- 5 . 6 3 9 5}$ & $\mathbf{- 5 . 2 5 9 5}$ & $\mathbf{- 4 . 7 0 2 7}$ & $\mathbf{8 5 . 0 7 1 4}$ & $\mathbf{0 . 0 0 0 0}$ \\
\hline MSIAH(3)-VAR(5) & $\mathbf{5 8 1 . 0 5 6 8}$ & $\mathbf{- 5 . 6 8 2 5}$ & $\mathbf{- 5 . 0 9 0 6}$ & $\mathbf{- 4 . 2 2 3 3}$ & $\mathbf{1 5 0 . 6 3 8 2}$ & $\mathbf{0 . 0 0 0 0}$ \\
\hline MSM(2)-VAR(5) & 513.4372 & -5.5050 & -5.2931 & -4.9826 & 15.3990 & 0.0074 \\
\hline MSM(3)-VAR(5) & 519.6045 & -5.5069 & -5.2511 & -4.8764 & 27.7336 & 0.0004 \\
\hline MSMH(2)-VAR(5) & 525.9669 & -5.6133 & -5.3795 & -5.0368 & 40.4584 & 0.0000 \\
\hline MSMH(3)-VAR(5) & 534.9489 & -5.6131 & -5.3135 & -4.8745 & 58.4224 & 0.0000 \\
\hline
\end{tabular}

If Table 2,3,4,5 and 6 are summarized, first the most powerful kind of MS-VAR models are MSIAH, MSIH and MSAH for our variables. Second, models with four lag are more successful than other models. The impulse response function of MS-VAR models doesn't work with MSIAH-VAR and MSAH-VAR models. Because of this reason we choose the most powerful MSIH-VAR model and analyze it.

The coefficients of the selected model are shown on the Table 7.

In the regime 1 (recession) and regime 2 (moderate growth) the constants of the dependent variables are very close to each other (Index LG (-0.0936, 0.0104); Index HG $(-0.0909,0.0141))$. With reference to the constants, we may expect a similar movement from two indices in the recession regime and moderate growth regime. In the regime 3 (expansion), the constant of the model which describes Index LG (0.0413) is bigger than the constant of the model which describes Index HG (0.0285). In the expansion regime, we may watch a stronger movement from the Index LG. As given on table, the relationship between Index HG and it's lags is both negative $(-0.1147,-0.0572,-0.1766$, -0.2127). However, the relations between Index HG and the lags of the Index LG are mostly positive $(0.2337,-0.0102,0.2615,0.3598)$.

While examining the relationship between Index LG and it's lags, it is observed that the coefficients of the first and second lags are negative. However, the coefficients of the third and fourth lags are positive. Conversely in the same model, the coefficients 
of the first and second lags of Index HG are positive although the coefficients of the third and fourth lags are negative.

Table 7: Coefficients

\begin{tabular}{|c|c|c|}
\hline & $\begin{array}{c}\text { INDEX HIGH } \\
\text { GROWTH }\end{array}$ & $\begin{array}{c}\text { INDEX LOW } \\
\text { GROWTH }\end{array}$ \\
\hline Constant (Regime 1) & -0.0909 & -0.0936 \\
\hline Constant (Regime 2) & 0.0141 & 0.0104 \\
\hline Constant (Regime 3) & 0.0285 & 0.0413 \\
\hline INDEX HIGH GROWTH -1 & -0.1147 & 0.1040 \\
\hline INDEX HIGH GROWTH -2 & -0.0572 & 0.0694 \\
\hline INDEX HIGH GROWTH -3 & -0.1766 & -0.0789 \\
\hline INDEX HIGH GROWTH -4 & -0.2127 & -0.1127 \\
\hline INDEX LOW GROWTH -1 & 0.2337 & -0.0678 \\
\hline INDEX LOW GROWTH -2 & -0.0102 & -0.1297 \\
\hline INDEX LOW GROWTH -3 & 0.2615 & 0.1203 \\
\hline INDEX LOW GROWTH -4 & 0.3598 & 0.2325 \\
\hline Standard Error (Regime 1) & 0.1153 & 0.0669 \\
\hline Standard Error (Regime 2) & 0.0594 & 0.0430 \\
\hline Standard Error (Regime 3) & 0.1135 & 0.0343 \\
\hline
\end{tabular}

Table 4 shows the probabilities of regime transitions. If equity markets in any day are known as they are in regime 1; the following day the markets are expected to be $61.27 \%$ in regime $1,08.61 \%$ in regime 2 and $30.12 \%$ in regime 3 . For instance if the indices' returns are negative in any day, the returns are expected to be $61.27 \%$ negative at the end of the following day. If the markets are known as they are in regime 2; the following observation is expected to be $98.65 \%$ in regime $2,01.22 \%$ in regime 1 and $00.12 \%$ in regime 3 . If the market is known as it is in regime 3 ; the following observation is expected to be $83.91 \%$ in regime $3,11.34 \%$ in regime 1 and $04.75 \%$ in regime 2. If the markets' volatilities are high and the returns are positive in any day, the next day's returns are expected to be $83.91 \%$ positive. The international investors might do their portfolio selection due to this information.

Table 4: Transition Probabilities

\begin{tabular}{|l|c|c|c|}
\hline & Regime 1 & Regime 2 & Regime 3 \\
\hline Regime 1 & 0.6127 & 0.0861 & 0.3012 \\
\hline Regime 2 & 0.0122 & 0.9865 & 0.0012 \\
\hline Regime 3 & 0.1134 & 0.0475 & 0.8391 \\
\hline
\end{tabular}

In the observation period, regime 2 has the maximum number of observation (135) the highest probability (81.76) and the highest duration (74.12). If market is in moderate growth, expected duration is 74 month. The minimum number of observation (13), the minimum probability (0.0613) and the minimum duration belongs to regime 1 . The durations of recession regime (2.58) and expansion regime (6.22) are very short while compared with the moderate growth regime (74.12).

Table 5: Regime Probabilities

\begin{tabular}{|l|c|c|c|}
\hline & Number of Observations & Probability & Duration \\
\hline Regime 1 & 13 & 0.0613 & 2.58 \\
\hline Regime 2 & 135 & 0.8176 & 74.12 \\
\hline Regime 3 & 28 & 0.1211 & 6.22 \\
\hline
\end{tabular}


The contemporaneous correlations of the indices are shown in the next tables. This type of correlation shows the correlation between two time series in the same regime. The highest correlation is found in the moderate growth regime, although the lowest correlation is found in the expansion regime.

Table 6: Contemporaneous Correlation-Regime 1

\begin{tabular}{|l|l|l|}
\hline & INDEX HIGH GROWTH & INDEX LOW GROWTH \\
\hline INDEX HIGH GROWTH & 1 & 0.5305 \\
\hline INDEX LOW GROWTH & 0.5305 & 1 \\
\hline
\end{tabular}

Table 7: Contemporaneous Correlation-Regime 2

\begin{tabular}{|l|l|l|}
\hline & INDEX HIGH GROWTH & INDEX LOW GROWTH \\
\hline INDEX HIGH GROWTH & 1 & 0.5781 \\
\hline INDEX LOW GROWTH & 0.5781 & 1 \\
\hline
\end{tabular}

Table 8: Contemporaneous Correlation -Regime 3

\begin{tabular}{|l|l|l|}
\hline & INDEX HIGH GROWTH & INDEX LOW GROWTH \\
\hline INDEX HIGH GROWTH & 1 & 0.4771 \\
\hline INDEX LOW GROWTH & 0.4771 & 1 \\
\hline
\end{tabular}

The probabilities of the regimes are shown in the next figure. The longest observation belongs to regime 2 (more than 7 years) called as moderate growth.

Figure 4: Regime Probabilities

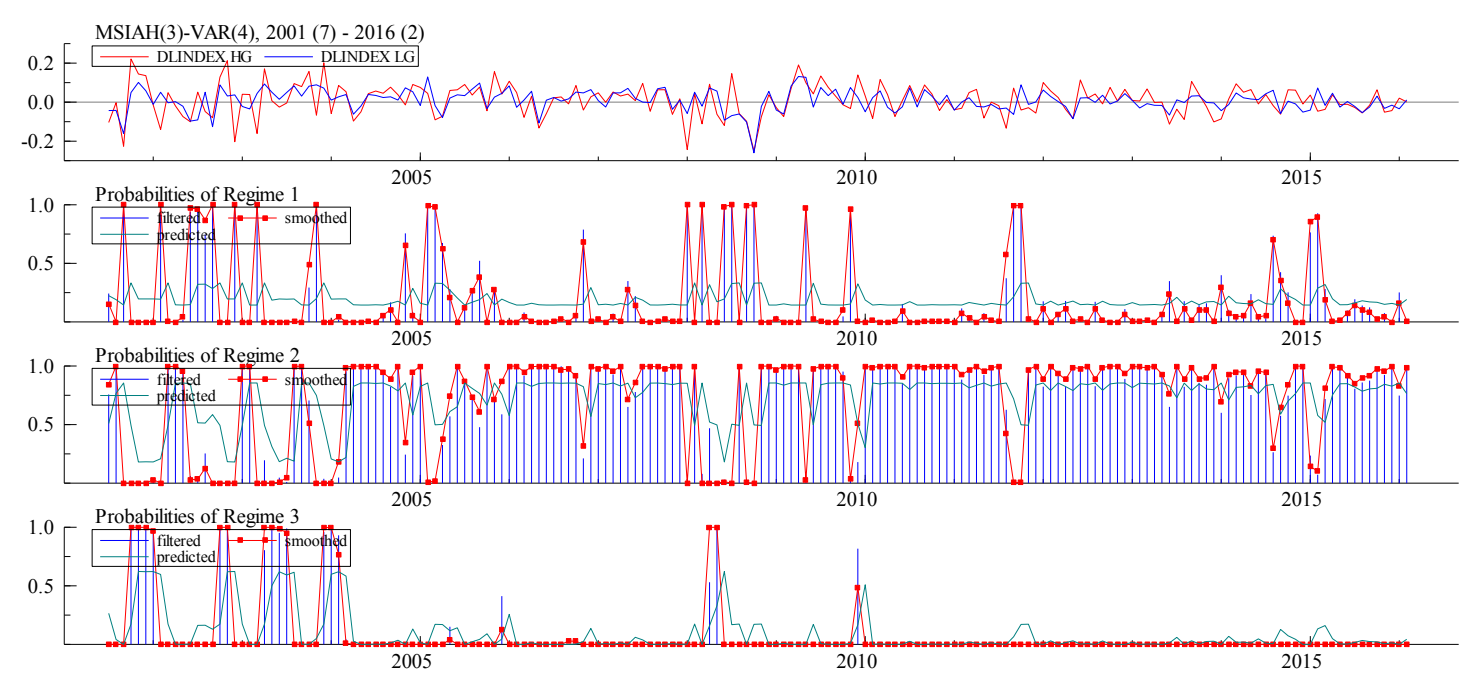

Table 9 shows the details of the cycle dates. The recession regime of the model captures the September 11 attacks which were a series of four coordinated terrorist attacks by the Islamic terrorist group Al-Qaeda. After the second plane crashed into the World Trade Center, the trading in New York Stock Exchange (NYSE) and NASDAQ were cancelled. London Stock Exchange and some other stock exchanges around the world were closed too. Besides, the model captures the 2008 Global Crisis which is the last important stock market crash. 
Table 9: Cycle Dates

\begin{tabular}{|l|l|l|}
\hline Regime 1 : Recession & Regime 2: Moderate Growth & Regime 3: Expansion \\
\hline $2001: 8-2001: 9[0.7463]$ & $2004: 2-2007: 12[0.9865]$ & $2001: 7-2001: 7[0.3768]$ \\
$2002: 5-2002: 9[0.8555]$ & $2008: 11-2016: 2[0.9940]$ & $2001: 10-2002: 4[0.9560]$ \\
$2008: 1-2008: 1[0.9819]$ & & $2002: 10-2004: 1[0.9522]$ \\
$2008: 6-2008: 10[0.9994]$ & & $2008: 2-2008: 5[0.9673]$ \\
\hline
\end{tabular}

The results of the impulse-response functions of the MSIH(3)-VAR(3) model are shown in Figure 5. The first line is regime 1, the second line is regime 2 and the last line is regime 3. In the first column the shock is applied to Index High Growth and in the second column to Index Low Growth.

Figure 5: Impulse Response Tests

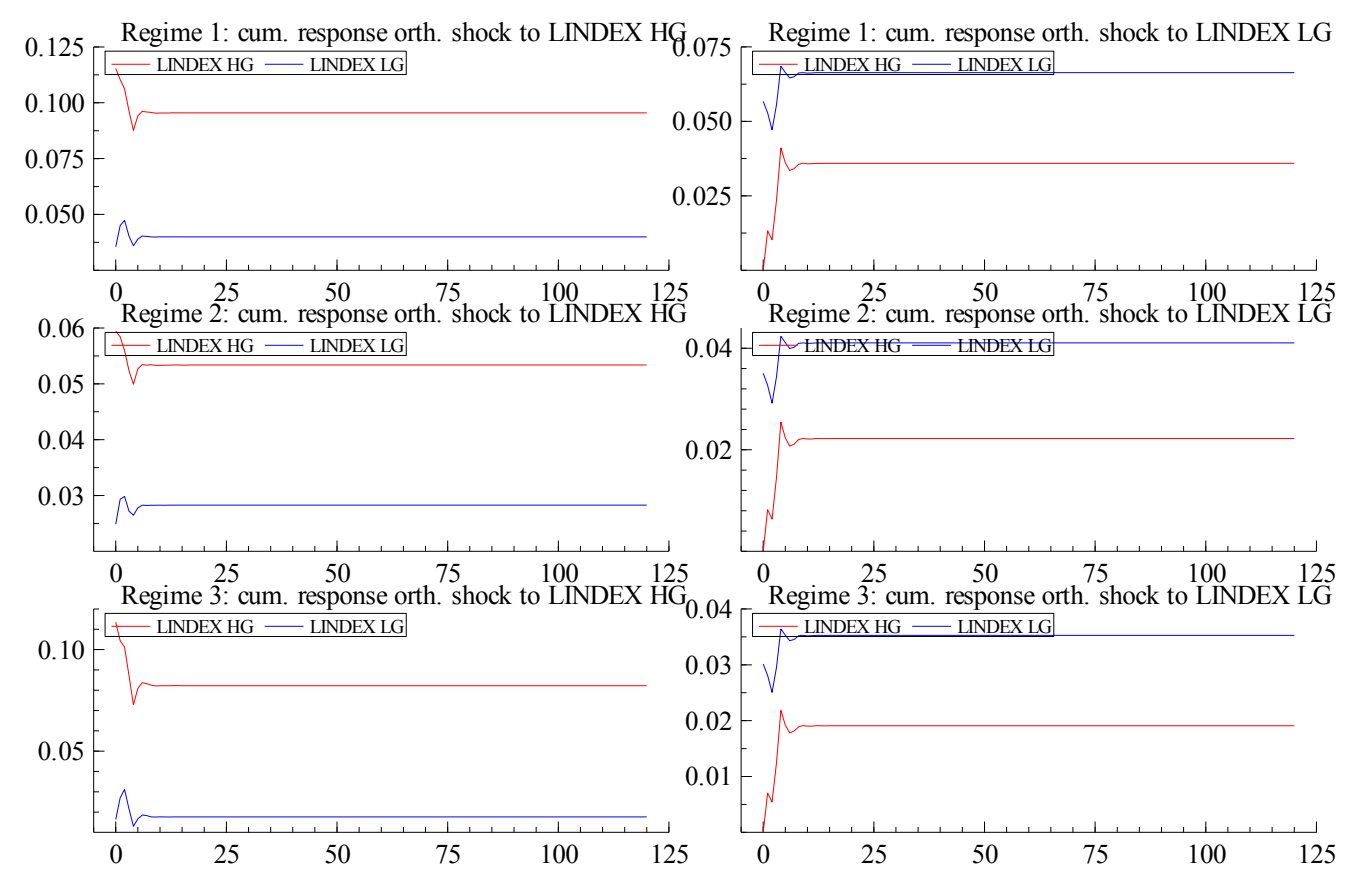

If one standard deviation's shock is applied to Index HG;

Regime 1: Index LG rises in the first month nearly 0.05 , then falls to nearly 0.03 and lasts by 0.03 . The biggest response is in the recession regime.

Regime 2: Index LG rises in the first month nearly 0.03 , then falls to nearly 0.028 and lasts by 0.028 .

Regime 3: Index LG rises in the first month nearly 0.025 , falls to nearly 0.01 and lasts by 0.01 . The minimum lasting effect is in the expansion regime.

If one standard deviation's shock is applied to Index LG;

Regime 1: Index HG rises in the first month nearly 0.04 , falls to nearly 0.035 and lasts by 0.035 . The biggest response and the maximum lasting effect is in the recession regime.

Regime 2: Index HG rises in the first month nearly 0.026 , falls to nearly 0.023 and lasts by it.

Regime 3: Index HG rises in the first month nearly 0.021 , falls to nearly 0.020 and lasts by it. The minimum lasting effect is in the expansion regime. 


\section{Conclusion}

In this study, we have investigated two main subjects. The main purpose of the study is to investigate whether a mutual regime switching behavior exists in the selected equity markets. The other purpose is to investigate the importance of growth of the selected economies which the equity markets belong.

The MRS models which represent the most important example of non-linear time series models of current application are used in the study. The financial markets are observed with fast and frequent fluctuations which are also might seen as the recession and expansion regimes. MRS models successfully capture the regimes in the financial markets. We find many kinds of MRS models explaining the relationship. The model $\operatorname{MSIH}(\mathrm{M})-\mathrm{VAR}(\mathrm{p})$ is the best describing model. Model with "Markov switching", "Intercept regime dependent", "heteroskedastic", "Vector autoregressive" characteristics is used to analyze 2001:01-2016:2 period. MSIH(3)-VAR(4) model by minimum Schwarz Criteria and maximum LR Linearity have three regimes and four autoregressive lags. The first regime in the model is recession, the second is moderate growth and the third is expansion. The variance distinguishes moderate growth and expansion regime from each other. When the variance and/or volatility of regime moderate growth is relatively low, it is high in the expansion regime.

It is observed that the coefficients of both index HG and the index LG in recession and moderate growth regime is very close together. Only the coefficient of index LG in regime expansion is relatively high to index HG. The high probability of staying in the same regime by transition possibilities supports the model as correctly identified. It is noteworthy by regime probabilities that duration is high in the second regime moderate growth. This model shows the market's possibility of staying longest in average (74 months) that is moderate growth regime in which volatility is lower than others. It is an evidence that the investors take a long-term investment decisions in low volatile and moderate growing markets. The highest correlation between the indices belongs to moderate growth regime.

The impulse response analysis shows that a standard deviation shock applied to one of the index for all regimes caused a positive response on the other indices in the first month. As direction of the reaction is same, the size and persistence varies according to regime and indices. Another important result is that the model captures the global crisis 2008 and September 11 attacks by cycle date.

The probabilities and durations of the regime switching mechanism of this model are important for international investors in selecting portfolios. The investors may select the stocks according to the duration and probabilities of the regimes. For instance if the market is high volatile and returns are positive, they should expect this returns for maximum 6 months. After nearly six months the regime should change. First, in any day the investors might examine the returns, volatility, and suppose which regime the information shows. Second they should decide the portfolio selection by using the probabilities and durations.

The study presents evidence for variables affecting emerging stock markets on the integration process with international markets and existence of unobservable state variables in these markets. It is indicated that the low or high growth speed of the economies emerging markets does not change the response of these markets to the new information. The regimes created by the fluctuations in financial markets lead the international markets to move in the same direction. 


\section{References}

Ang, A., Timmermann, A., (2011). "Regime Changes and Financial Markets", NBER Working, Paper No. 17182

Arestis, P., Demetriades, P. O., Luintel, K. B. (2001). "Financial Development and Economic Growth: The Role of Stock Markets", Journal of Money, Credit and Banking, Vol. 33, No. 1, 16-41.

Balcilar, M., Ozdemir, Z. A. (2013). "Asymmetric and Time-Varying Causality between Inflation and Inflation Uncertainity in G-7 Countries" Scottish Journal of Political Economy Vol. 60, No. 1, 1-42.

Balcilar, M., Gupta, R., Wohar, M.E. (2015) "Common Cycles and Common Trends in the Stock and Oil markets: Evidence from More than 150 Years of Data", Department of Economics Working Paper Series, 2015-72.

Beck, T., Levine, R. (2004). "Stock markets, banks, and growth: Panel evidence", Journal of Banking \& Finance, Vol. 28, No. 3, 423-442.

Bildirici, M., E., Aykaç Alp, E., Ersin, Ö. Ö., Bozoklu, Ü. (2010). İktisatta Kullanılan Doğrusal Olmayan Zaman Serisi Yöntemleri, İstanbul: Türkmen Kitabevi.

Çevik, E. İ., Korkmaz, T., Atukeren, E. (2012). "Business confidence and stock returns in the USA: a time-varying Markov regime-switching model", Applied Financial Economics, No. 22, 299-312

Dorina, L., Simina, U., (2006). "Testing Efficiency of the Stock Market in Emerging Economies", The Journal of the Faculty of Economics-Economic Science Series, No. 2, 827-831.

Gozbasi, O. (2015). "Interaction between stock market development and economic growth: Evidence from developing countries", Eskisehir Osmangazi University Journal of Economics and Administrative Sciences, Vol. 10, No. 2,: 269-284.

Guidolin, M., Timmermann. A. (2006) "An econometric model of nonlinear dynamics in the joint distribution of stock and bond returns" Journal of Applied Econometrics Vol. 21, No. 1, 1-22.

Guidolin M. "Modelling, Estimating and Forecasting Financial Data under Regime (Markov) Switching"

http://didattica.unibocconi.it/mypage/dwload.php?nomefile=Lecture 7 _Markov_Switching_Models20130520235704.pdf, (accessed 30.03.2016).

Gürbüz, A. O. (2004). Dünya'dan ve Türkiye'den Örneklerle Hesaplama Yöntemlerine Göre Hisse Senedi Endeksleri ve Yatırımcı İlgisini Yansıtan Bir Endeks Önerisi. İstanbul: Yaylım Yayıncılık.

Hamilton J. D. (1989). "A New Approach to the Economic Analysis of Nonstationary Time Series and the Business Cycle”, Econometrica, Vol. 57, No. 2, 357-384.

Hamilton J. D., Susmel, R. (1994). "Autoregressive conditional heteroskedasticity and changes in regime", Journal of Econometrics, Vol.64, No. 1-2, 307-333.

Harrison, B., Moore W., "Nonlinearities in Stock Returns for Some Recent Entrants to The EU", Discussion Papers in Economics, Nottingham Trent University. No.2010/1.

Kaplan, M. 2008 "The Impact of Stock Market on Real Economic Activity: Evidence from Turkey", Journal of Applied Sciences, Vol. 8, No. 2:, 374-378. 
Kim, S., Kim, S.Y., Choi, K. (2017) "Modeling and analysis for stock return movements along with exchange rates and interest rates in Markov regimeswitching models", Cluster Computing, https://doi.org/10.1007/s10586-017-15197, In press.

Kolb, R. W., Overdahl., J. D. (2007) Futures, Options and Swaps., Fifth Ed., UK: Blackwell Publishing.

Krolzig H. M. (2000). "Predicting Markov-Switching Vector Autoregressive Processes" Working Paper 2000W310xford University.

Lim, K. P., Chee, W. H. (2012) "Non-Linear Predictability in G7 Stock Index Returns", The Manchester School, Vol. 81, No. 4, 620-637.

Marcucci, J. (2005) "Forecasting Stock Market Volatility with Regime-Switching GARCH Models", Studies in Nonlinear Dynamics \& Econometrics, Vol. 9, No. 4, $1-55$.

Nazer, S. B., Samir G. (2007) "Stock markets, banks, and economic growth: Empirical evidence from the MENA region", Research in International Business and Finance, No. 21, 297-315.

Ngare, E., Nyamongo, E. M., Misati, R. N. (2014). "Stock market development and economic growth in Africa", Journal of Economics and Business, No.74, 24-39.

Nielsen S., Olesen, J. O. (2000). "Regime-Switching Stock Returns and Mean Reversion" Working paper 11-2000.

Perez-Quiros, G., Timmermann, A. (2001). "Business cycle asymmetries in stock returns: Evidence from higher order moments and conditional densities", Journal of Econometrics, Vol. 103, No. 1, 259-306.

Rousseau, P. L., Wachtel, P. 2000. "Equity markets and growth: Cross-country evidence on timing and outcomes, 1980-1995", Journal of Banking \& Finance, Vol. 24, No. 12, 1933-1957.

Schaller H., Norden, S. V. (1997). "Regime switching in stock market returns", Applied Financial Economics, No. 7, 177- 191.

Schwert, G. W. (1989). "Why does stock Market Volatility Change Over Time?”, The Journal of Finance, Vol.44, No.5., 1115-1153.

Seddighi, H. R., Nian, W. (2004). “The Chinese stock exchange market: Operations and efficiency", Applied Financial Economics, No. 14, 785-797.

Song, W., Ryu, D., Webb, R. I. (2016), "Overseas Market Shocks and VKOSPI Dynamics: A Markov Switching Approach”, Finance Research Letters, Vol.16, 275-282.

Zhu, H., Su, X., You, W., Reni Y. (2016), "Asymmetric effects of oil price shocks on stock returns: evidence from a two-stage Markov regime-switching approach", Applied Aconomics, Vol. 49, No. 25, 2491-2507. 